\title{
Echocardiography and cardiac resynchronisation therapy, friends or foes?
}

\author{
W.M. van Everdingen $\cdot$ J.C. Schipper $\cdot$ J. van 't Sant $\cdot$ K. Ramdat Misier $\cdot$ M. Meine $\cdot$ M.J. Cramer
}

Published online: 8 December 2015

(C) The Author(s) 2015. This article is published with open access at Springerlink.com

\begin{abstract}
Echocardiography is used in cardiac resynchronisation therapy (CRT) to assess cardiac function, and in particular left ventricular (LV) volumetric status, and prediction of response. Despite its widespread applicability, LV volumes determined by echocardiography have inherent measurement errors, interobserver and intraobserver variability, and discrepancies with the gold standard magnetic resonance imaging. Echocardiographic predictors of CRT response are based on mechanical dyssynchrony. However, parameters are mainly tested in single-centre studies or lack feasibility. Speckle tracking echocardiography can guide LV lead placement, improving volumetric response and clinical outcome by guiding lead positioning towards the latest contracting segment. Results on optimisation of CRT device settings using echocardiographic indices have so far been rather disappointing, as results suffer from noise. Defining response by echocardiography seems valid, although re-assessment after 6 months is advisable, as patients can show both continuous improvement as well as deterioration after the initial response. Three-dimensional echocardiography is interesting for future implications, as it can determine volume, dyssynchrony and viability in a single recording, although image quality needs to be adequate. Deformation patterns from the septum and the derived parameters are promising, although validation in a multicentre trial is required. We conclude that echocardiography has a pivotal role in CRT, although clinicians should know its shortcomings.
\end{abstract}

W.M. van Everdingen $(\bowtie) \cdot$ J.C. Schipper $\cdot$ J. van 't Sant ·

K. Ramdat Misier · M. Meine · M.J. Cramer

Department of Cardiology, University Medical Centre Utrecht,

Heidelberglaan 100,

PO Box 85500, 3508 GA Utrecht, The Netherlands

e-mail: w.m.vaneverdingen@umcutrecht.nl
Keywords Cardiac resynchronisation therapy · Echocardiography $\cdot$ Volume $\cdot$ Optimisation $\cdot$ Dyssynchrony · Response · Follow-up · Interobserver variability $\cdot$ Speckle tracking echocardiography $\cdot$ Deformation imaging · $3 \mathrm{D}$ echocardiography $\cdot$ Septal strain

\section{Introduction}

Thus far, echocardiography has a pivotal role in cardiac resynchronisation therapy (CRT), underlined by the wide field of application, determining cardiac function and specifically left ventricular (LV) function and response due to desired reverse electro-mechanical remodelling. The range of tools, from brightness mode or Doppler imaging to deformation imaging, offers the possibility of patient selection and response prediction, lead placement optimisation strategies and optimisation of device configurations (Fig. 1; [1-3]). Multiple single-centre studies have advocated the value of echocardiography in patient selection and determining prognosis [4-6]. However, limitations are known, as the PROSPECT study showed a limited value regarding response prediction, and EchoCRT gave insight into the potential negative effects of echocardiographic parameters as selection criteria [3,7]. Moreover, echocardiography can have a relatively substantial measurement error and not every patient is suitable for adequate echocardiographic volume assessment, especially in non-expert hands [8]. The question arises whether echocardiography is a useful imaging tool for evaluation of CRT patients, or are its shortcomings impeding clinical decision making? This review reflects on the role of echocardiography in the field of CRT, are they friends or foes? 


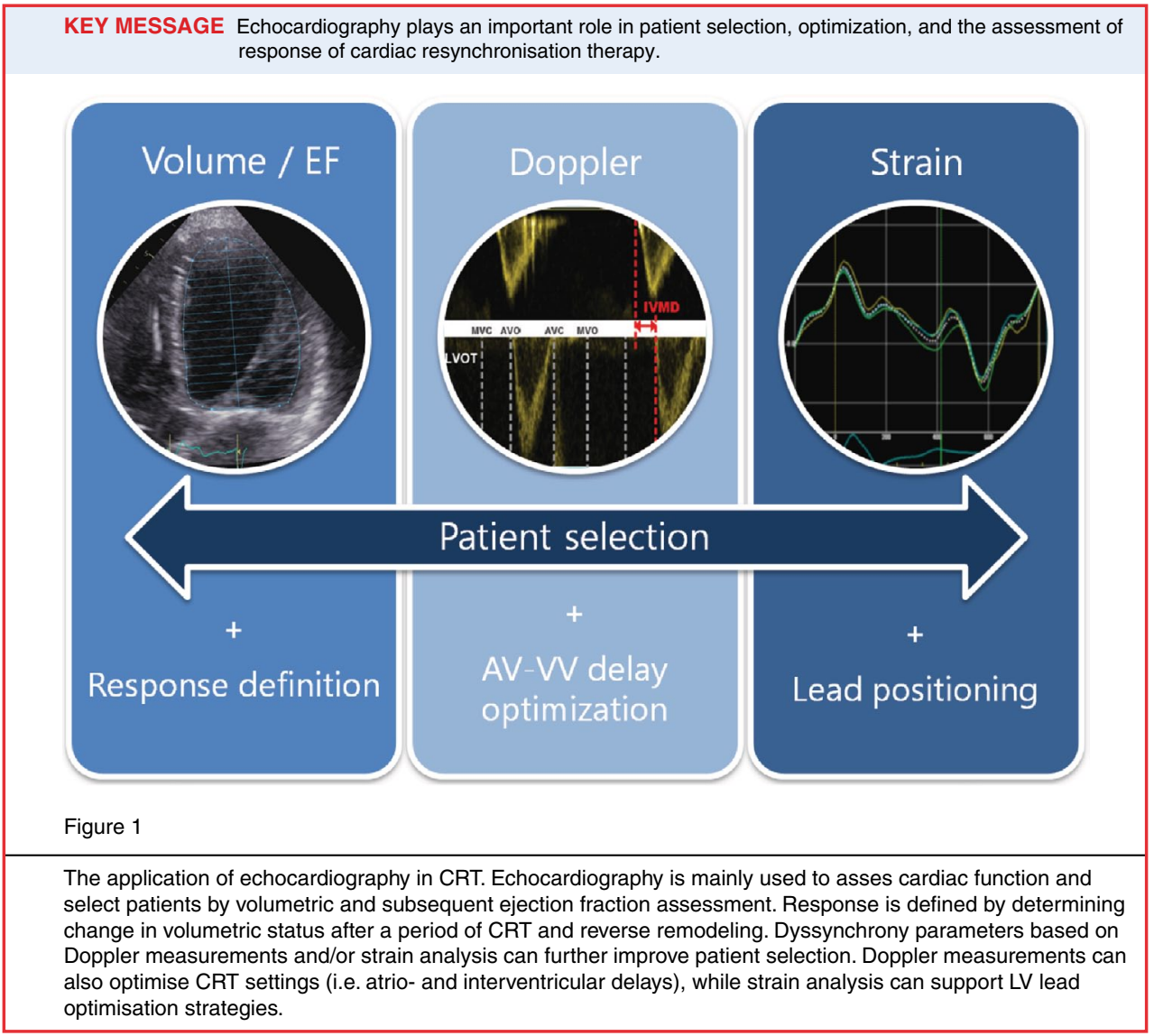

\section{Patient selection}

Left ventricular ejection fraction

Echocardiography gives insight into the cardiac anatomy and valvular dysfunction of CRT patients. Its main role in CRT is determining cardiac function and especially LV volumes and ejection fraction (LVEF). International guidelines on CRT define a cut-off for LVEF at $\leq 35 \%$, independent of the imaging tool used $[9,10]$. A meta-analysis of randomised trials on the effects of CRT on morbidity and mortality has underlined this cut-off. A reduced benefit or even adverse effect in patients with an LVEF above the cut-off was observed, although the large confidence interval might indicate that a subgroup of patients with LVEF $>35 \%$ do benefit (hazard ratio for all-cause mortality: 0.28-2.00) [11]. This could be due to an overestimation of LVEF by echocardiography. A sub-analysis of the PROSPECT study advocated the benefit of CRT in patients above the threshold [12]. The threshold for response to CRT is probably more a continuum than binary.

Although the biplane Simpson's method is the most robust method to determine LV volume and function for echocardiography, intraobserver and interobserver variability can be high, with reported differences in LVEF of up to $18 \%$ (Bland-Altman limits of agreement or two standard deviations) [8]. A study compared LVEF determined by a recruiting centre to an echocardiography core lab. The correlation coefficient was fair among 413 patients $\left(\mathrm{R}^{2}: 0.69\right)$. A mean difference of $0.2 \%$ was found, although a wide confidence interval was observed (95\% CI: $-17.4-17.8 \%)$. Moreover, $20 \%$ of all patients would have been reclassified by another centre, using a cut-off for LVEF of 30\% [13]. These results underline the limitations of echocardiography for a strict cut-off, beside the need for core lab activities.

Volumes derived with echo are underestimated compared with 'gold standard' magnetic resonance imaging (MRI) $[14,15]$. Nevertheless a meta-analysis found a mean difference between the two modalities of close to $0 \%$, although a large spread and heterogeneity between studies was observed [8]. Assessment of LVEF by MRI and echocardiography shows opposing results for CRT eligibility in $28 \%$ of patients, using the guideline cut-off. Compared with MRI, echocardiography underestimated both end-diastolic and end-systolic volume, while overestimating LVEF [15]. As most large multicentre trials on the selection of patients for CRT used echocardiographic-derived volumes, cut-offs cannot be directly translated to other imaging techniques.

Averaging of several measured beats improves accuracy in general, and is applicable to all patients and specifically 
in atrial fibrillation. Contrast-enhanced echocardiography for volume assessment can further reduce intraobserver and interobserver variability $[16,17]$. An intravenous contrast agent can identify the endocardial borders more precisely. When used in either two- or three-dimensional echocardiography, LV volumes determined by contrast are also more similar (less underestimated) to MRI [16]. Results on LVEF are conflicting, as both similar and improved correlations to MRI are reported using contrast-enhanced volumes compared with conventional echocardiography [16-18].

Based on these findings, the cut-off for selection of patients eligible for CRT should depend on the imaging tool. Moreover, subgroups for LVEF $30-40 \%$ could be incorporated in future guidelines [12]. Patients with LVEF above the current cut-off, but with a true left bundle branch block (LBBB), might benefit from CRT. Implementation of subgroups, in concordance with the role of QRS width in current guidelines, may reflect the role of LVEF in CRT more appropriately. However, evidence supporting CRT in subgroups based on LVEF needs to be further established.

\section{Dyssynchrony}

Selection criteria for patients eligible for CRT based on electrical or mechanical dyssynchrony show a preference for an electrical substrate [9]. Correcting mechanical dyssynchrony without an electrical substrate has proven to be ineffective, as has been shown in large trials such as EchoCRT [7]. Moreover, after PROSPECT, it remains debated whether mechanical dyssynchrony is warranted as an indicator for response to CRT, although the study design and applied dyssynchrony parameters are disputed [19]. Guidelines have so far been restricted to clinical and electrocardiographic selection criteria (i.e. QRS width and LBBB morphology). As previously mentioned, imaging tools are strictly necessary to determine LVEF. Mechanical dyssynchrony proven by any echocardiographic parameter is not included in current guidelines. Patients with a class I indication (i.e. LBBB) will most certainly have a form of mechanical dyssynchrony when assessed by echo. Patients with a class III indication (i.e. QRS $<120 \mathrm{~ms}$ ) and with proven dyssynchrony are no better or even worse with CRT $[7,20]$. The additional value of dyssynchrony parameters might be in the class IIa or b groups. In these groups, with prolonged QRS width ( $>120$ or $>150 \mathrm{~ms}$ ) and non-LBBB, visualised mechanical dyssynchrony could indicate a treatable substrate.

Mechanical dyssynchrony parameters (Table 1) should be based on a physiological principle, where early septal and delayed activation of the LV free wall causes disturbed $\mathrm{LV}$ intraventricular and interventricular interaction. An ideal parameter indicates a substrate that can be corrected by biventricular pacing. Prediction models for volumetric response ( $>15 \%$ decrease in end-systolic volume) advocate the use of mechanical dyssynchrony parameters, on top of existing criteria [21, 22]. However, multicentre trials and meta-analysis have failed to show an added value of several dyssynchrony indices, although interventricular mechanical dyssynchrony (IVMD) was associated with increased survival in the CARE-HF study [3, 23, 24]. Other parameters (systolic rebound stretch of the septum (SRSsept), septal flash and apical rocking) are only proven in single-centre studies $[4,25,26]$.

Visual assessment or 'eye-balling' of mechanical dyssynchrony is perhaps the most feasible method for routine clinical applications. Two parameters are known: apical rocking and septal flash (Fig. 2) Both are known to have a high specificity for predicting response [25, 26]. Apical rocking is the apical transverse motion due to an inhomogeneity of myocardial contraction and function, and requires an apical four chamber view with a visible apex. LBBB causes early septal contraction which moves the apex towards the septum, while delayed lateral wall contraction subsequently 'rocks' the apex towards the lateral side. Szulik et al. proved the predictive value for volumetric response, with comparable strength for both visually assessed and automatically quantified apical rocking [25]. Ghani et al. confirmed these results and further showed that apical rocking predicts longterm clinical outcome in terms of hospitalisation for heart failure [6]. Septal flash shows similar results. A septal flash is a short inward septal motion, occurring due to early septal contraction, interrupted by delayed free wall contraction. Parsai et al. found the presence of septal flash to be predictive for both clinical and volumetric response [27]. On top of known predictors, the value of septal flash in prediction models was significant [22].

IVMD is the delay in onset of outflow between the left and right ventricle. Delayed activation and subsequent contraction of the LV free wall due to LBBB leads to a delayed rise in LV pressure and outflow. LV dyssynchrony therefore lengthens the LV pre-ejection period, increasing IVMD, while 'normal' right ventricular (RV) activation leads to a fast rise in pressure and outflow through the RV outflow tract. IVMD can, however, be confounded by reduced RV function and a lengthened RV pre-ejection period. It can be easily measured using pulsed-wave Doppler signals obtained in any standard echocardiogram. IVMD reflects dyssynchrony of interventricular dynamics, by subtracting the difference in onset between QRSonset and flow through both the left and right ventricular outflow tract (LV and RV pre-ejection period, respectively). Although a cut-off of $40 \mathrm{~ms}$ is used to determine dyssynchrony, IVMD has a linear relationship with response, and a specific cut-off for response is unsuitable [28]. It is therefore not applicable for patient selection, although the probability of response can be determined. 
Table 1 Echocardiographic parameters for patient selection and/or response prediction

\begin{tabular}{|c|c|c|c|c|c|c|}
\hline $\begin{array}{l}\text { Param- } \\
\text { eter }\end{array}$ & Brief description & $\begin{array}{l}\text { Echocardiographic } \\
\text { image }\end{array}$ & Cut-off & Pros & Cons & Remarks \\
\hline $\begin{array}{l}\text { Apical } \\
\text { rocking }\end{array}$ & $\begin{array}{l}\text { Visual assessment of } \\
\text { apical rocking motion }\end{array}$ & AP4CH view ${ }^{\mathrm{a}}$ & Yes/no $[6,25]$ & Easy method & $\begin{array}{l}\text { Translating continuous } \\
\text { process to an on/off } \\
\text { phenomenon } \\
\text { Confounded by } \\
\text { RV-function }\end{array}$ & $\begin{array}{l}\text { Requires multi- } \\
\text { centre validation }\end{array}$ \\
\hline $\begin{array}{l}\text { Septal } \\
\text { flash }\end{array}$ & $\begin{array}{l}\text { Visual assessment of } \\
\text { short septal motion dur- } \\
\text { ing beginning of systole }\end{array}$ & $\begin{array}{l}\text { AP4CH view, zoomed on } \\
\text { septum or PLAX }\end{array}$ & Yes/no [26] & Easy method & $\begin{array}{l}\text { Interobserver } \\
\text { differences } \\
\text { Translation of continu- } \\
\text { ous process to on/off } \\
\text { phenomenon }\end{array}$ & $\begin{array}{l}\text { Requires multi- } \\
\text { centre validation }\end{array}$ \\
\hline IVMD & $\begin{array}{l}\text { Interventricular } \\
\text { mechanical delay, differ- } \\
\text { ence in onset of outflow } \\
\text { of LV (LVPEP) and RV } \\
\text { (RVPEP) }\end{array}$ & $\begin{array}{l}\text { Pulsed-wave Doppler of } \\
\text { LVOT and RVOT }\end{array}$ & $\begin{array}{l}40 \mathrm{~ms}[3,11, \\
21]\end{array}$ & $\begin{array}{l}\text { Relatively easy } \\
\text { method }\end{array}$ & $\begin{array}{l}\text { Ambiguous results in } \\
\text { multicentre trials } \\
\text { Confounded by both } \\
\text { LV and RV function }\end{array}$ & $\begin{array}{l}\text { Still indicates } \\
\text { probability of } \\
\text { response } \\
50 \text { ms cut-off } \\
\text { used in CARE- } \\
\text { HF trial [28] }\end{array}$ \\
\hline SRSsept & $\begin{array}{l}\text { All positive deflections } \\
\text { after initial shortening } \\
\text { of the septum during } \\
\text { systole }\end{array}$ & $\begin{array}{l}\text { AP4CH view suitable } \\
\text { for speckle tracking (B- } \\
\text { mode) zoomed and focus } \\
\text { on septum }\end{array}$ & $\begin{array}{l}4.7 \%[4,21, \\
31,38]\end{array}$ & $\begin{array}{l}\text { Predicts volu- } \\
\text { metric response } \\
\text { and outcome }\end{array}$ & $\begin{array}{l}\text { Relatively difficult for } \\
\text { non-trained personnel } \\
\text { GE specific } \\
\text { Interobserver } \\
\text { differences }\end{array}$ & $\begin{array}{l}\text { One trial found } \\
4.0 \% \text { as cut-off } \\
\text { using entire AP- } \\
4 \mathrm{CHimages} \mathrm{[32]} \\
\text { Requires multi- } \\
\text { centre validation }\end{array}$ \\
\hline $\begin{array}{l}\text { Septal } \\
\text { strain } \\
\text { patterns }\end{array}$ & $\begin{array}{l}\text { Strain pattern of the } \\
\text { septum during systole }\end{array}$ & $\begin{array}{l}\text { AP4CH view suitable } \\
\text { for speckle tracking (B- } \\
\text { mode) zoomed and focus } \\
\text { on septum }\end{array}$ & $\begin{array}{l}3 \text { types }(1 \\
\text { and } 2 \text { often } \\
\text { responder, } \\
\text { 3: often non- } \\
\text { responder) } \\
{[33,34]}\end{array}$ & $\begin{array}{l}\text { Predicts volu- } \\
\text { metric response } \\
\text { and outcome }\end{array}$ & $\begin{array}{l}\text { Relatively difficult for } \\
\text { non-trained personnel }\end{array}$ & $\begin{array}{l}\text { Requires multi- } \\
\text { centre validation }\end{array}$ \\
\hline SL delay & $\begin{array}{l}\text { Difference of time to } \\
\text { peak velocity (or short- } \\
\text { ening) of (basal) septal } \\
\text { and lateral wall }\end{array}$ & $\begin{array}{l}\text { AP4CH view suitable } \\
\text { for speckle tracking (B- } \\
\text { mode) or TDI velocity } \\
\text { delay }\end{array}$ & $\geq 65 \mathrm{~ms}[3,5]$ & $\begin{array}{l}\text { Predicts volu- } \\
\text { metric response } \\
\text { and outcome }\end{array}$ & $\begin{array}{l}\text { Negative results in } \\
\text { multicentre trial } \\
\text { Large influence of } \\
\text { sampling } \\
\text { Time-to-peak based }\end{array}$ & \\
\hline SD-TTP & $\begin{array}{l}\text { Standard deviation of } \\
\text { time to peak shorten- } \\
\text { ing (strain) or velocity } \\
\text { (TDI) off all myocardial } \\
\text { segments }\end{array}$ & $\begin{array}{l}\text { AP4CH, AP2CH and } \\
\text { APLAX view suitable } \\
\text { for speckle tracking (B- } \\
\text { mode) or TDI }\end{array}$ & $\geq 32 \mathrm{~ms}[3]$ & & $\begin{array}{l}\text { Time-to-peak based } \\
\text { High image quality } \\
\text { needed }\end{array}$ & $\begin{array}{l}\text { Requires multi- } \\
\text { centre validation }\end{array}$ \\
\hline SDI & $\begin{array}{l}\text { Time to minimal systolic } \\
\text { volume of } 16 \text { segments }\end{array}$ & 3D echocardiography & $9.8 \%$ [39] & $\begin{array}{l}\text { High predictive } \\
\text { value for } \\
\text { response }\end{array}$ & $\begin{array}{l}\text { Limited spatial and } \\
\text { temporal resolution }\end{array}$ & $\begin{array}{l}\text { Requires multi- } \\
\text { centre validation }\end{array}$ \\
\hline
\end{tabular}

AP4CH apical four chamber view, $B$-mode brightness mode, $G E$ General Electric, $I V M D$ interventricular mechanical delay, $L V$ left ventricle, $L V O T$ left ventricular outflow tract, $L V P E P$ left ventricular pre-ejection period, $P L A X$ parasternal long axis, $S D I$ systolic dyssynchrony index, $S D$-TTP standard deviation of time to peak shortening, $R V$ right ventricular, $R V O T$ right ventricular outflow tract, $R V P E P$ right ventricular pre-ejection period, SL-delay septal to lateral wall delay of time to peak shortening, SRSsept systolic rebound stretch of the septum, TDI tissue Doppler imaging.

\section{Deformation imaging}

Deformation imaging or strain analysis with echocardiography uses either tissue Doppler imaging or speckle tracking echocardiography. The latter is less angle dependent and covers the whole ventricular wall, in contrast to tissue Doppler imaging, and is therefore more reliable for detection of delayed activated segments.

Septal to lateral wall delay (SL delay) is obtained by either tissue Doppler velocity imaging or speckle tracking echocar- diography, calculated by the time difference between peak velocity (Doppler) or contraction (Doppler and/or speckle tracking) of the basal septal and lateral wall [5]. SL delay thereby reflects both early septal and late lateral wall contraction caused by delayed free wall activation. Using tissue Doppler imaging, SL delay is measured by sampling in the basal septal and lateral wall, which is sensitive to sample placement [29]. As for all time-based parameters, defining the maximum peak is of importance. The maximal peak can be early or late, depending on the interaction with tether- 
Fig. 2 Central illustration. Role of echocardiography in CRT. Echocardiography can be used to select patients by volume and subsequent ejection fraction assessment and by dyssynchrony parameters based on Doppler and/ or strain analysis. Doppler can also optimise CRT settings, while strain analysis could support LV lead optimisation strategies

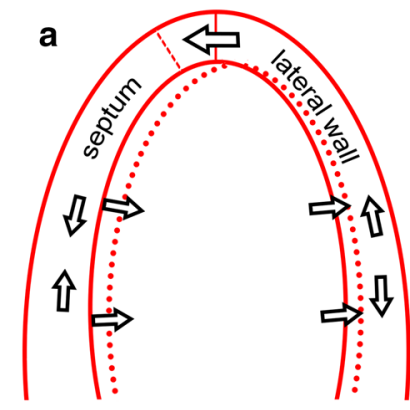

b

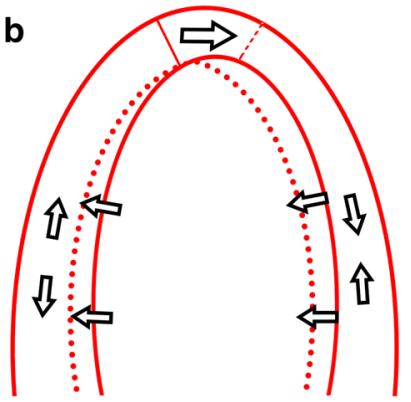

ing myocardium and ventricular dynamics. Septal deformation can have a late maximum peak, while contraction starts early, resulting in an earlier first peak (baseline septal strain in Fig. 3). A dyssynchronous ventricle can therefore be deemed synchronous. Moreover, despite the promising results of single-centre studies, so far no multicentre trial has proved the diagnostic power of SL delay [3].

Most deformation parameters use time delays in peak contraction, either absolute, relative or as a standard deviation, to determine evidence of dyssynchrony [30]. These parameters suffer from the same definition-based limitations as SL delay. Parameters that incorporate the entire strain curve are therefore more promising. Moreover, highquality images are required to determine segmental differences, which is not always feasible, especially in patients with dilated ventricles due to heart failure. The interventricular septum is therefore of particular interest, as echocardiographic imaging of the septum is almost always feasible and reproducible. Its central position in the ultrasound window guarantees adequate image quality. Moreover, the septum provides information on interventricular interaction as well as intraventricular properties. Derived parameters, such as SRSsept or identification of septal strain patterns, are promising as predictors of outcome (Fig. 3 and Table 2; [4, 31, 32]). SRSsept is the total amount of systolic rebound stretch, after initial shortening of the septum. Early septal shortening disrupted by contralateral delayed free wall contraction causes rebound stretch. SRSsept thereby assesses the amount of wasted work for the septum that can be recruited by CRT. Septal dyssynchrony can show multiple typical patterns, of which Leenders et al. discriminated three types [33]. These patterns (and SRSsept) are even influenced by myocardial viability and predict both clinical and volumetric response to CRT (Fig. 3; [33, 34]). Risum et al. recently demonstrated the role of LV strain pattern recognition on top of electrocardiographic predictors for outcome [35]. However, results depend on the ultrasound machine and speckle tracking echocardiography software used. The majority of algorithms to determine myocardial strain are unknown and lack validation. Inter-vendor differences are known and limit translation to other ultrasound machines than the most commonly published, i.e. GE EchoPac, General Elec- tric Healthcare, Milwaukee, USA [36]. Intraobserver and interobserver coefficients of variation are relatively high for SRSsept (19.5 and 16.3\%, respectively) [4]. Despite the small number of clinical trials, all agree on the potential strength of septal strain parameters derived by speckle tracking echocardiography (Table 1; [32, 34, 37, 38]). A multicentre trial is required to prove their benefit in clinical decision making.

Dyssynchrony can also be assessed by three-dimensional echocardiography (3DE). The predominant 3DE parameter is the systolic dyssynchrony index, using the standard deviation of difference from a reference time point in the QRS complex to minimal systolic volume of 16 segments. Systolic dyssynchrony index (mean cut-off 9.8\%) was able to predict treatment response with a sensitivity and specificity of 93 and $75 \%$ respectively [39]. The intra-class correlation coefficients for intraobserver and interobserver variability were high (0.95 and 0.92 respectively). Nevertheless, the echocardiographic image quality (i.e. spatial and temporal resolution) needs to be adequate for analysis, which is not always feasible. QRS triggering should also be adequate, as triggering after QRS onset will miss early septal contraction, overestimate the onset and therefore underestimate time-to-peak values. Moreover, these parameters have been tested in single-centre studies, and therefore require validation in a multicentre trial. The diagnostic power of the systolic dyssynchrony index can therefore be overrated, as has been observed for previous parameters (e.g. SL delay) $[3,5]$.

\section{Optimising lead position}

Radial strain obtained with speckle tracking echocardiography from parasternal short axis images prior to implantation can indicate segments with delayed peak contraction. During implantation, LV lead placement can be guided to these segments, resulting in a remote, adjacent (i.e. neighbouring), or concordant placement, based on the 17-segment model of the American Heart Association. Observational studies have shown that a concordant or adjacent position to the latest contracting segment is superior to a remote 

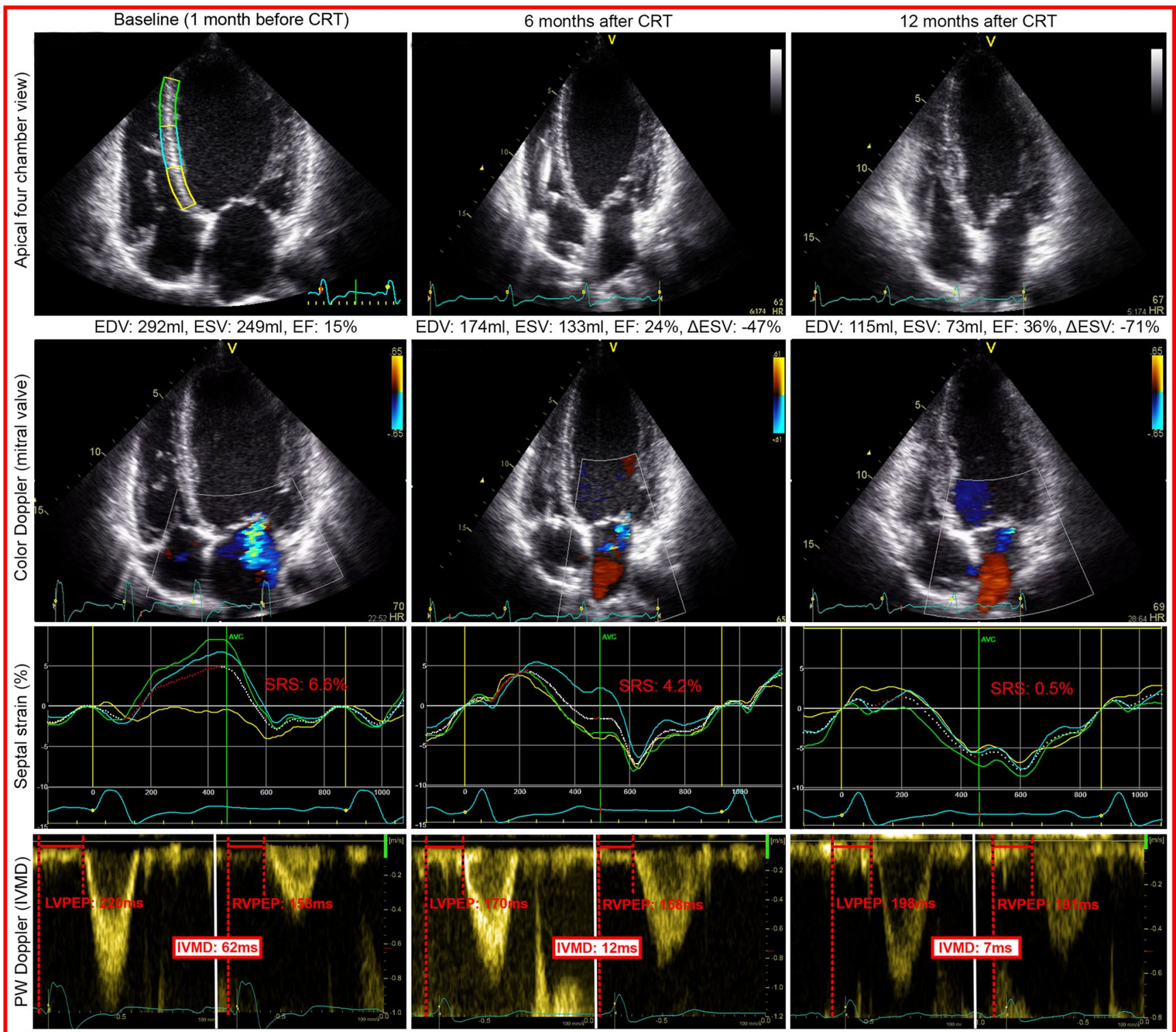

Fig. 3 Schematic representation of apical rocking and septal flash. Schematic representation of the left ventricle in echocardiographic apical four-chamber view, showing both septal flash and apical rocking due to LBBB-induced mechanical dyssynchrony. a Early septal contraction stretches the lateral wall and rocks the apex to the left, while the septum thickens and moves inwards. b Late lateral wall contraction stretches the septum and rocks the apex to the right. c Relaxation of the lateral wall with continuing septal contraction, while the apex moves to its original position position, in terms of reverse remodelling, death and hospitalisation during 2 years of follow-up [40, 41]. Targeting the latest contracting segment with radial strain has been implemented in two randomised clinical trials, the TARGET and STARTER trial. Patients were randomised to targeted or conventional LV lead placement [1, 42]. Targeted placement led to a higher percentage of concordant or adjacent positions and showed improvement in both volumetric response (LV change in end-systolic volume, TARGET: $-30 \pm 29$ vs. $-20 \pm 25 \%$ and STARTER: $-46 \pm 33$ vs. $-26 \pm 23 \mathrm{ml}$ ) and clinical outcome (percentage of patients reaching endpoint of death and hospitalisation for heart failure, TARGET: 22 vs. $42 \%$ and STARTER: 14 vs. $21 \%$ ). A large number of leads in the unguided group were by chance placed in a favourable position. Per-protocol analysis of both studies showed that patients (guided or unguided) with concordant or adjacently placed leads had a better response and outcome [1, 42].

Another advantage of strain analysis is information on myocardial viability by peak strain values. Scarred regions are known to have lower strain amplitudes, and pacing in a region of scar tissue correlates to non-response [43]. 


\section{Advertisement placed here.}

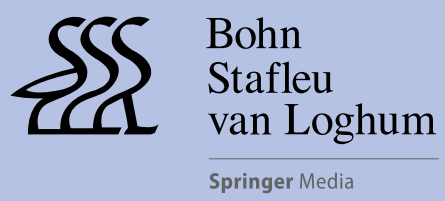

Houten 2015 


\title{
Advertisement placed here.
}

\author{
CC Bohn \\ Stafleu \\ van Loghum \\ Springer Media
}

Houten 2015 
Table 2 Studies on septal dyssynchrony parameters predicting response to CRT

\begin{tabular}{|c|c|c|c|c|c|c|}
\hline First author & Design & Subjects $(n)$ & $\begin{array}{l}\text { Parameter and } \\
\text { cut-off }\end{array}$ & $\begin{array}{l}\text { Response prediction } \\
(\geq 15 \% \Delta \mathrm{ESV})\end{array}$ & Outcome & $\begin{array}{l}\text { Strengths and/or } \\
\text { limitations }\end{array}$ \\
\hline De Boeck [4] & $\begin{array}{l}\text { Prospective single } \\
\text { centre }\end{array}$ & 62 & SRSsept $>4.7 \%$ & $\begin{array}{l}\text { Sens/spec: } 81 \% / 81 \% \text {, } \\
\text { AUC: } 0.938 \pm 0.035, \mathrm{~B} \text { : } \\
2.41, p=0.005\end{array}$ & & $\begin{array}{l}\text { Relatively high } \\
\text { inter- and intra- } \\
\text { observer variabil- } \\
\text { ity (COV: } 14.2 \text { and } \\
15.6 \%)\end{array}$ \\
\hline Leenders [31] & $\begin{array}{l}\text { Prospective single } \\
\text { centre }\end{array}$ & 101 & SRSsept $>4.7 \%$ & $\begin{array}{l}\text { Multivariate analysis, } \\
\text { B: } 3.78, p<0.001\end{array}$ & $\begin{array}{l}\text { Survival (death, } \\
\text { LVAD or trans- } \\
\text { plant) with HR: } \\
5.8(2.3-14.3)\end{array}$ & $\begin{array}{l}\text { No HF hospitalisa- } \\
\text { tion or morbidity }\end{array}$ \\
\hline Chan [38] & $\begin{array}{l}\text { Prospective single } \\
\text { centre }\end{array}$ & 43 & SRSsept $>4.7 \%$ & AUC: $0.862 \pm 0.061^{\mathrm{a}}$ & & $\begin{array}{l}\text { No multivariate } \\
\text { analysis }\end{array}$ \\
\hline van ’t Sant [21] & $\begin{array}{l}\text { Retrospective single } \\
\text { centre }\end{array}$ & 227 & $\begin{array}{l}\text { SRSsept } \\
\text { (continuous) }\end{array}$ & $\begin{array}{l}\text { Multivariate analysis, } \\
\text { B: } 1.191\end{array}$ & & $\begin{array}{l}\text { SRSsept assessed as } \\
\text { continuous variable. } \\
\text { No specific cut-off } \\
\text { used }\end{array}$ \\
\hline Ghani [32] & $\begin{array}{l}\text { Retrospective single } \\
\text { centre }\end{array}$ & 138 & SRSsept $>4.0 \%$ & $\begin{array}{l}\text { Sens/spec: } 66 \% / 66 \% \text {, } \\
\text { AUC: } 0.70\end{array}$ & $\begin{array}{l}\text { Data on outcome } \\
\text { not published (al- } \\
\text { though registered) }\end{array}$ & $\begin{array}{l}\text { Analysis on AP4CH } \\
\text { instead of septal } \\
\text { single wall }\end{array}$ \\
\hline Leenders [33] & $\begin{array}{l}\text { Retrospective single } \\
\text { centre }\end{array}$ & 132 & $\begin{array}{l}\text { Septal deforma- } \\
\text { tion patterns }(3 \\
\text { types) }\end{array}$ & $\begin{array}{l}\text { Type } 1 \text { and } 2 \text { predict } \\
\text { response vs type } 3 \\
\Delta \mathrm{ESV}: 37 \pm 20 \& \\
24 \pm 24 \text { vs } 5 \pm 20 \mathrm{ml} \\
p<0.001\end{array}$ & & $\begin{array}{l}\text { Validated by mecha- } \\
\text { nistic computer } \\
\text { model }\end{array}$ \\
\hline Marechaux [34] & $\begin{array}{l}\text { Prospective single } \\
\text { centre }\end{array}$ & 101 & $\begin{array}{l}\text { Septal deforma- } \\
\text { tion patterns }(3 \\
\text { types) }\end{array}$ & $\begin{array}{l}\text { Responders: pattern } \\
1 \& 2 \text { vs 3: } 92 \text { vs. } 59 \% \text {, } \\
p<0.0001 \text {, Sens/spec: } \\
74 \% / 74 \%\end{array}$ & $\begin{array}{l}18 \text { months event- } \\
\text { free survival } \\
\text { (death or HF hos- } \\
\text { pitalisation): Pat- } \\
\text { tern } 1 \& 2 \text { vs. } 3: 95 \\
\text { vs } 75 \%, p=0.01\end{array}$ & $\begin{array}{l}\text { Relatively short } \\
\text { follow-up }\end{array}$ \\
\hline Risum [37] & $\begin{array}{l}\text { Prospective single } \\
\text { centre }\end{array}$ & 67 & $\begin{array}{l}\text { LBBB deforma- } \\
\text { tion pattern }\end{array}$ & Sens/spec: $91 \% / 95 \%$ & & $\begin{array}{l}\text { Complex pattern } \\
\text { description }\end{array}$ \\
\hline Risum [35] & $\begin{array}{l}\text { Prospective } \\
\text { multicentre }\end{array}$ & 208 & $\begin{array}{l}\text { LBBB deforma- } \\
\text { tion pattern }\end{array}$ & & $\begin{array}{l}\text { Absence of } \\
\text { LBBB-pattern } \\
\text { increases } 4 \text { year } \\
\text { risk of death, } \\
\text { HF hospitalisation, } \\
\text { LVAD or HTx HR } \\
3.1(1.64-5.88)\end{array}$ & $\begin{array}{l}\text { Complex pattern } \\
\text { description }\end{array}$ \\
\hline
\end{tabular}

Studies on septal dyssynchrony parameters, derived from speckle tracking echocardiography, predicting response to cardiac resynchronization therapy. All studies are single centre, prospective trials.

$A U C$ area under the curve in ROC analysis, $B$ beta-coefficient, $C O V$ coefficient of variation, $\triangle E S V$ difference in end-systolic volume, $H F$ heart failure, $H R$ hazard ratio, $H T x$ heart transplantation, $L B B B$ left bundle branch block, $L V A D$ left ventricular assist device, $n$ number of patients, $p$ p-value, sens sensitivity, spec specificity, SRSsept systolic rebound stretch of the septum.

${ }^{a}$ when added to a model with clinical characteristics (gender, LBBB, QRS duration, heart failure aetiology).

Both abovementioned trials excluded segments with peak strain $<10 \%$, thereby excluding potentially scarred segments, which may have contributed significantly to the positive effects of echo-guided lead positioning. Sub-analysis showed that absence of scar near the LV lead was a strong predictor for volumetric response and reduced all-cause mortality in the TARGET trial [44]. Moreover, sub-analysis of the STARTER trial indicated that echo-guided LV lead placement improved survival especially in patients with ischaemic cardiomyopathy [45]. Notwithstanding these results, peak radial strain has shortcomings as an indicator for viability, as the sensitivity and specificity were only 33 and $72 \%$ respectively, compared with MRI with delayed enhancement [46]. Peak strain values might be underestimated in a dyssynchronous ventricle, as both pre- and rebound stretch would decrease the absolute peak value.

High image quality is important for reliable strain analysis, which is relatively difficult to obtain in typical CRT patients with dilated left ventricles. Segments distal from the echo probe (i.e. basal and mid-inferoseptal, inferior and inferolateral segments) are prone to noise, and therefore result in more random strain curves. Even if quality is sufficient, time-to-peak strain values can be quite comparable between segments, as can be appreciated in Fig. 4 . 

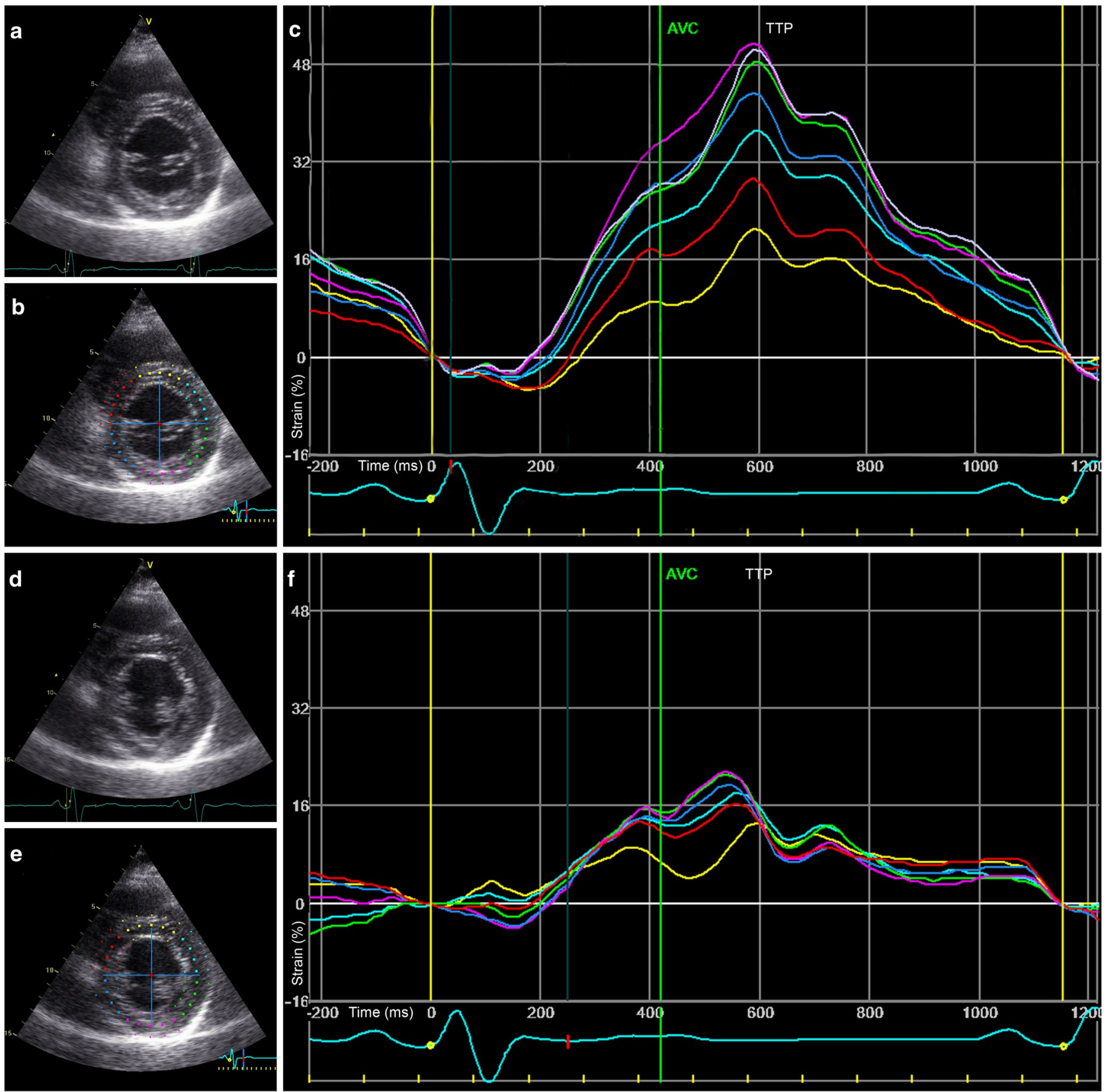

Fig. 4 Example of echocardiographic data obtained from a responder to CRT. Apical four-chamber view, colour Doppler, septal strain and pulsed-wave Doppler acquisition of a responder to CRT, before, and 6 and 12 months after implantation. Note the continuous decrease in LV volume, decrease in mitral regurgitation, improvement in septal strain and decrease in IVMD over time. These data suggest a continuous process of reverse remodelling. Septal strain: yellow, light blue and green lines represent basal, mid and apical inferoseptal segmental strain, respectively. The three curves represent the segments illustrated in baseline echocardiogram in the upper left panel. The white dashed curve represents the average septal strain. SRSsept is marked red, as all rebound stretch after initial shortening, during systole. IVMD is represented by pulsed-wave Doppler signals of the left and right ventricular outflow tract. $E D V$ end-diastolic volume, $E S V$ end-systolic volume, $E F$ ejection fraction, $\triangle E S V$ change in ESV compared with baseline, SRS systolic rebound stretch, LVPEP left ventricular preejection period, RVPEP right-ventricular pre-ejection period, IVMD interventricular mechanical delay. Volumes are derived by biplane Simpson's method

identical between recordings, which means that changes in heart rhythm disturb the result. 3DE could be an answer to the above-mentioned difficulties, assessing the entire left pring longitudinal strain could be a solution, it has more
pronounced regional differences and is more robust than radial strain [47]. Lastly, loading conditions need to be 
ventricle in a single recording, although current techniques require multiple consecutive beats [48].

\section{Optimisation of device configuration}

Echocardiography can be used to optimise atrioventricular and/or interventricular delays (AV/VV delay). AV-delay optimisation influences ventricular filling and may cause fusion with intrinsic conduction, thereby also influencing intraventricular and interventricular interaction. VV-delay optimisation also influences intraventricular and interventricular dynamics, leading to more homogenous LV contraction. Optimisation methods used in previous trials are: iterative or Ritter method of mitral valve inflow characteristics, velocity time integral of Doppler echocardiography of LVOT, and dyssynchrony indices using visual assessment, speckle tracking echocardiography or tissue Doppler imaging. Optimisation influences acute haemodynamic and mechanical interaction [49]. Van Deursen et al. showed the interaction between electrocardiography, strain analysis by speckle tracking echocardiography, IVMD, velocity time integral of the LVOT, and blood pressure based on finger plethysmography, while adjusting either the AV or VV delay in CRT patients [49].

Optimisation has comparable results on long-term outcome to standard or fixed delays [50]. The SMART-AV study, for example, showed no benefit of echocardiographic optimisation with an iterative method compared with a fixed AV delay of $120 \mathrm{~ms}$ [2]. Although Mullens et al. showed that $47 \%$ of clinical non-responders (no significant New York Heart Association (NYHA) class or 6-minute walking test improvement) had a suboptimal AV delay, no trials so far have been published on the effects of optimisation on change in volumetric response [51]. Except for the unpublished RESPONSE-HF study, which showed no benefit of VV-delay optimisation in non-responders in a preliminary report [50]. All echocardiographic optimisation methods optimise relatively small changes (10-20 ms difference in $\mathrm{AV}$ and/or VV delay) with a parameter prone to noise. Patient repositioning, breathing, echocardiographic probe displacement, and other physiological disturbances all influence results. Even if one were to overcome the first three, reliable and reproducible measurement requires numerous iterations [52, 53]. This implies even more time-consuming protocols, which are unlikely to be used by clinicians. Moreover, blinding observers for settings using the iterative method leads to an even larger spread in optimums compared with unblinded optimisation, suggesting a significant amount of observer bias [47]. The optimal AV delay can also differ during different physiological conditions (i.e. rest and exercise) and may change due to remodelling $[54,55]$.
These limitations currently make echocardiography unsuitable for optimisation.

\section{Defining response with echocardiography}

For response prediction, an echocardiogram is performed at least 6 months after CRT implantation, to compare volumetric status pre- and post-implantation (after a period of preferred reverse remodelling). Reverse remodelling is characterised by a decrease in $\mathrm{LV}$ volume. $\mathrm{A} \geq 15 \%$ decrease in LV end-systolic volume is commonly used to define response to CRT, or if lower, non-response. Although clinical response to CRT is multifactorial and is observed in patients without remodelling, volumetric change (i.e. decrease in end-systolic volume) predicts clinical response and prognosis of CRT patients. A larger decrease in endsystolic volume means fewer hospitalisations for heart failure and a lower mortality rate. When divided into subgroups (negative, non-responder, normal, and super-responder), there is an upscaling effect. Super-responders had almost no events during 5 years of follow-up, while non and negative responders have progressive heart failure and subsequent events [56]. Moreover, end-systolic volume decrease is preferred over clinical parameters (NYHA class, 6-minute walking distance, and quality of life score [57]. Quality of life and reverse remodelling do not always overlap, as patients can show improvement in one without the other [58]. Clinical parameters should not be disregarded, as an increase in quality of life or NYHA class can be as important to a patient as survival. Health status responders, defined by the Kansas City Cardiomyopathy Questionnaire (KCCQ) score, have a $76 \%$ lower risk of subsequent events [58]. A reason for the missing link could be the time of volumetric assessment [59]. Studies have shown that reverse remodelling is a continuous process, with patients still showing improvement after a year of CRT (Fig. 3; [28]). Patients who are below the threshold of response at 6 months could become responders afterwards. Even patients with a proven response can have a reversal in effect, as volumetric assessment 14 months after initial response can show an increase in end-systolic volume to pre-CRT levels [60]. Assessment after 14 months of CRT proved to be a better predictor of major adverse cardiac events. These results necessitate a continuous re-evaluation of volumetric status.

\section{Future directions}

Echocardiography could play a larger role in CRT, especially if $3 \mathrm{D}$ acquisition were to become more feasible for clinical practice. Increased spatial and temporal resolution could make 3DE applicable for fast acquisition of volumet- 
ric status and myocardial strain [14, 39]. A single acquisition could therefore incorporate information on function, volume, viability, dyssynchrony, and options for LV lead positioning.

Although validation in a large multicentre trial is required, dyssynchrony parameters based on patterns (i.e. SRSsept and strain patterns) instead of timing are promising for response prediction. These indices define a treatable substrate of dyssynchrony and have shown their predictive value in several studies [31,35].

Patients with LVEF $>35 \%$ (especially in patients with LBBB) are an interesting group for further research. These individuals might benefit from CRT. Whether their LV volumes should be determined by echocardiography or MRI and whether guidelines should distinguish between the technique used, also requires further study. Lastly, measurement variability should be addressed for reliable assessment. Measuring and averaging multiple beats should be common practice, although not all software tools incorporate average values for volume and ejection fraction (i.e. Xcelera, Philips).

\section{Conclusion}

Echocardiography is a practical clinical tool and used for assessment of volumetric status, function and outcome in CRT patients (central illustration). Clinicians should know its shortcomings when implementing results in clinical decision making. Specific cut-off values determined by a less accurate technique require a lenient approach. So far, response prediction and patient selection by mechanical dyssynchrony parameters have been disappointing. However a new set of parameters (i.e. deformation imaging) has shown promising results in single-centre studies and requires a multicentre approach to prove its benefit. While implementation of AV or VV delay optimisation is difficult with current techniques, deformation parameters may guide LV lead placement, increasing response rates and improving prognosis. We therefore conclude that echocardiography is a friend of CRT, with known limitations. Their relationship could become even stronger, with promising applications of $3 \mathrm{DE}$ and deformation imaging to patient selection and optimisation of lead placement.

\section{Funding None.}

\section{Conflict of interests None declared.}

Open Access This article is distributed under the terms of the Creative Commons Attribution License which permits any use, distribution, and reproduction in any medium, provided the original author(s) and the source are credited.

\section{References}

1. Khan FZ, Virdee MS, Palmer CR, et al. Targeted left ventricular lead placement to guide cardiac resynchronization therapy: the TARGET study: a randomized, controlled trial. J Am Coll Cardiol. 2012;59(17):1509-18.

2. Ellenbogen KA, Gold MR, Meyer TE, et al. Primary results from the SmartDelay determined AV optimization: a comparison to other AV delay methods used in cardiac resynchronization therapy (SMART-AV) trial: a randomized trial comparing empirical, echocardiography-guided, and algorithmic atrioventricular delay programming in cardiac resynchronization therapy. Circulation. 2010;122(25):2660-8.

3. Chung ES, Leon AR, Tavazzi L, et al. Results of the Predictors of Response to CRT (PROSPECT) trial. Circulation. 2008;117(20):2608-16.

4. De Boeck BW, Teske AJ, Meine M, et al. Septal rebound stretch reflects the functional substrate to cardiac resynchronization therapy and predicts volumetric and neurohormonal response. Eur J Heart Fail. 2009;11(9):863-71.

5. Bax JJ, Bleeker GB, Marwick TH, et al. Left ventricular dyssynchrony predicts response and prognosis after cardiac resynchronization therapy. J Am Coll Cardiol. 2004;44(9):1834-40.

6. Ghani A, Delnoy PP, Ottervanger JP, et al. Apical rocking is predictive of response to cardiac resynchronization therapy. Int J Cardiovasc Imaging. 2015;31(4):717-25.

7. Ruschitzka F, Abraham WT, Singh JP, et al. Cardiac-resynchronization therapy in heart failure with a narrow QRS complex. N Engl J Med. 2013;369(15):1395-405.

8. Wood PW, Choy JB, Nanda NC, Becher H. Left ventricular ejection fraction and volumes: it depends on the imaging method. Echocardiography. 2014;31(1):87-100.

9. Brignole M, Auricchio A, Baron-Esquivias G, et al. 2013 ESC Guidelines on cardiac pacing and cardiac resynchronization therapy: the Task Force on cardiac pacing and resynchronization therapy of the European Society of Cardiology (ESC). Developed in collaboration with the European Heart Rhythm Association (EHRA). Eur Heart J. 2013;34(29):2281-329.

10. Russo AM, Stainback RF, Bailey SR, et al. ACCF/HRS/AHA/ ASE/HFSA/SCAI/SCCT/SCMR 2013 appropriate use criteria for implantable cardioverter-defibrillators and cardiac resynchronization therapy: a report of the American College of Cardiology Foundation appropriate use criteria task force, Heart Rhythm Society, American Heart Association, American Society of Echocardiography, Heart Failure Society of America, Society for Cardiovascular Angiography and Interventions, Society of Cardiovascular Computed Tomography, and Society for Cardiovascular Magnetic Resonance. Heart Rhythm. 2013;10(4):e11-58.

11. Cleland JG, Abraham WT, Linde C, et al. An individual patient meta-analysis of five randomized trials assessing the effects of cardiac resynchronization therapy on morbidity and mortality in patients with symptomatic heart failure. Eur Heart J. 2013;34(46):3547-56.

12. Chung ES, Katra RP, Ghio S, et al. Cardiac resynchronization therapy may benefit patients with left ventricular ejection fraction $>35 \%$ : a PROSPECT trial substudy. Eur J Heart Fail. 2010;12(6):581-7.

13. Kaufmann BA, Min SY, Goetschalckx K, et al. How reliable are left ventricular ejection fraction cut offs assessed by echocardiography for clinical decision making in patients with heart failure? Int J Cardiovasc Imaging. 2013;29(3):581-8.

14. Driessen MM, Kort E, Cramer MJ, et al. Assessment of LV ejection fraction using real-time $3 \mathrm{D}$ echocardiography in daily practice: direct comparison of the volumetric and speckle tracking methodologies to CMR. Neth Heart J. 2014;22(9):383-90. 
15. Haan S de, Boer K de, Commandeur J, Beek AM, Rossum AC van, Allaart CP. Assessment of left ventricular ejection fraction in patients eligible for ICD therapy: discrepancy between cardiac magnetic resonance imaging and 2D echocardiography. Neth Heart J. 2014;22(10):449-55.

16. Hoffmann R, Barletta G, Bardeleben S von, et al. Analysis of left ventricular volumes and function: a multicenter comparison of cardiac magnetic resonance imaging, cine ventriculography, and unenhanced and contrast-enhanced two-dimensional and three-dimensional echocardiography. J Am Soc Echocardiogr. 2014;27(3):292-301.

17. Malm S, Frigstad S, Sagberg E, Larsson H, Skjaerpe T. Accurate and reproducible measurement of left ventricular volume and ejection fraction by contrast echocardiography: a comparison with magnetic resonance imaging. J Am Coll Cardiol. 2004;44(5):1030-5.

18. Saloux E, Labombarda F, Pellissier A, et al. Diagnostic value of three-dimensional contrast-enhanced echocardiography for left ventricular volume and ejection fraction measurement in patients with poor acoustic windows: a comparison of echocardiography and magnetic resonance imaging. J Am Soc Echocardiogr. 2014;27(10):1029-40.

19. Marwick TH. Hype and hope in the use of echocardiography for selection for cardiac resynchronization therapy: the Tower of Babel revisited. Circulation. 2008;117(20):2573-6.

20. Thibault B, Harel F, Ducharme A, et al. Cardiac resynchronization therapy in patients with heart failure and a QRS complex $<120$ milliseconds: the Evaluation of Resynchronization Therapy for Heart Failure (LESSER-EARTH) trial. Circulation. 2013;127(8):873-81.

21. Van 't Sant J, Ter Horst IA, Wijers SC, et al. Measurements of electrical and mechanical dyssynchrony are both essential to improve prediction of CRT response. J Electrocardiol. 2015;48(4):601-8.

22. Brunet-Bernard A, Marechaux S, Fauchier L, et al. Combined score using clinical, electrocardiographic, and echocardiographic parameters to predict left ventricular remodeling in patients having had cardiac resynchronization therapy six months earlier. Am J Cardiol. 2014;113(12):2045-51.

23. Anderson LJ, Miyazaki C, Sutherland GR, Oh JK. Patient selection and echocardiographic assessment of dyssynchrony in cardiac resynchronization therapy. Circulation. 2008;117(15):2009-23.

24. Cleland JG, Daubert JC, Erdmann E, et al. The effect of cardiac resynchronization on morbidity and mortality in heart failure. $\mathrm{N}$ Engl J Med. 2005;352(15):1539-49.

25. Szulik M, Tillekaerts M, Vangeel V, et al. Assessment of apical rocking: a new, integrative approach for selection of candidates for cardiac resynchronization therapy. Eur J Echocardiogr. 2010;11(10):863-9.

26. Sohal M, Amraoui S, Chen Z, et al. Combined identification of septal flash and absence of myocardial scar by cardiac magnetic resonance imaging improves prediction of response to cardiac resynchronization therapy. J Interv Card Electrophysiol. 2014;40(2):179-90.

27. Parsai C, Baltabaeva A, Anderson L, Chaparro M, Bijnens B, Sutherland GR. Low-dose dobutamine stress echo to quantify the degree of remodelling after cardiac resynchronization therapy. Eur Heart J. 2009;30(8):950-8.

28. Ghio S, Freemantle N, Scelsi L, et al. Long-term left ventricular reverse remodelling with cardiac resynchronization therapy: results from the CARE-HF trial. Eur J Heart Fail. 2009;11(5):480-8.

29. De Boeck BW, Meine M, Leenders GE, et al. Practical and conceptual limitations of tissue Doppler imaging to predict reverse remodelling in cardiac resynchronisation therapy. Eur J Heart Fail. 2008;10(3):281-90.
30. Leenders GE, Cramer MJ, Bogaard MD, Meine M, Doevendans PA, De Boeck BW. Echocardiographic prediction of outcome after cardiac resynchronization therapy: conventional methods and recent developments. Heart Fail Rev. 2011;16(3):235-50.

31. Leenders GE, De Boeck BW, Teske AJ, et al. Septal rebound stretch is a strong predictor of outcome after cardiac resynchronization therapy. J Card Fail. 2012;18(5):404-12.

32. Ghani A, Delnoy PP, Adiyaman A, et al. Septal rebound stretch as predictor of echocardiographic response to cardiac resynchronization therapy. Int J Cardiol Heart Vasc. 2015;7:6.

33. Leenders GE, Lumens J, Cramer MJ, et al. Septal deformation patterns delineate mechanical dyssynchrony and regional differences in contractility: analysis of patient data using a computer model. Circ Heart Fail. 2012;5(1):87-96.

34. Marechaux S, Guiot A, Castel AL, et al. Relationship between two-dimensional speckle-tracking septal strain and response to cardiac resynchronization therapy in patients with left ventricular dysfunction and left bundle branch block: a prospective pilot study. J Am Soc Echocardiogr. 2014;27(5):501-11.

35. Risum N, Tayal B, Hansen TF, et al. Identification of typical left bundle branch block contraction by strain echocardiography is additive to electrocardiography in prediction of long-term outcome after cardiac resynchronization therapy. J Am Coll Cardiol. 2015;66(6):631-41.

36. Everdingen WM van, Paiman ML, Deursen CJ van, et al. Comparison of septal strain patterns in dyssynchronous heart failure between speckle tracking echocardiography vendor systems. J Electrocardiol. 2015;48(4):609-16.

37. Risum N, Jons C, Olsen NT, et al. Simple regional strain pattern analysis to predict response to cardiac resynchronization therapy: rationale, initial results, and advantages. Am Heart J. 2012;163(4):697-704.

38. Chan YH, Wu LS, Kuo CT, et al. Incremental value of inefficient deformation indices for predicting response to cardiac resynchronization therapy. J Am Soc Echocardiogr. 2013;26(3):307-15.

39. Kleijn SA, Aly MF, Knol DL, et al. A meta-analysis of left ventricular dyssynchrony assessment and prediction of response to cardiac resynchronization therapy by three-dimensional echocardiography. Eur Heart J Cardiovasc Imaging. 2012;13(9):763-75.

40. Ypenburg C, Bommel RJ van, Delgado V, et al. Optimal left ventricular lead position predicts reverse remodeling and survival after cardiac resynchronization therapy. J Am Coll Cardiol. 2008;52(17):1402-9.

41. Kristiansen HM, Vollan G, Hovstad T, Keilegavlen H, Faerestrand $\mathrm{S}$. The impact of left ventricular lead position on left ventricular reverse remodelling and improvement in mechanical dyssynchrony in cardiac resynchronization therapy. Eur Heart J Cardiovasc Imaging. 2012;13(12):991-1000.

42. Saba S, Marek J, Schwartzman D, et al. Echocardiography-guided left ventricular lead placement for cardiac resynchronization therapy: results of the Speckle Tracking Assisted Resynchronization Therapy for Electrode Region trial. Circ Heart Fail. 2013;6(3):427-34.

43. Wong JA, Yee R, Stirrat J, et al. Influence of pacing site characteristics on response to cardiac resynchronization therapy. Circ Cardiovasc Imaging. 2013;6(4):542-50.

44. Khan FZ, Virdee MS, Read PA, et al. Effect of low-amplitude two-dimensional radial strain at left ventricular pacing sites on response to cardiac resynchronization therapy. J Am Soc Echocardiogr. 2010;23(11):1168-76.

45. Daya HA, Alam MB, Adelstein E, et al. Echocardiography-guided left ventricular lead placement for cardiac resynchronization therapy in ischemic vs nonischemic cardiomyopathy patients. Heart Rhythm. 2014;11(4):614-9. 
46. Bakos Z, Ostenfeld E, Markstad H, et al. A comparison between radial strain evaluation by speckle-tracking echocardiography and cardiac magnetic resonance imaging, for assessment of suitable segments for left ventricular lead placement in cardiac resynchronization therapy. Europace. 2014;16(12):1779-86.

47. Jones S, Shun-Shin MJ, Cole GD, et al. Applicability of the iterative technique for cardiac resynchronization therapy optimization: full-disclosure, 50-sequential-patient dataset of transmitral Doppler traces, with implications for future research design and guidelines. Europace. 2014;16(4):541-50.

48. Aly MF, Kleijn SA, Boer K de, et al. Comparison of three-dimensional echocardiographic software packages for assessment of left ventricular mechanical dyssynchrony and prediction of response to cardiac resynchronization therapy. Eur Heart J Cardiovasc Imaging. 2013;14(7):700-10.

49. Deursen CJ van, Wecke L, Everdingen WM van, et al. Vectorcardiography for optimization of stimulation intervals in cardiac resynchronization therapy. J Cardiovasc Transl Res. 2015;8(2):128-37.

50. Auger D, Hoke U, Bax JJ, Boersma E, Delgado V. Effect of atrioventricular and ventriculoventricular delay optimization on clinical and echocardiographic outcomes of patients treated with cardiac resynchronization therapy: a meta-analysis. Am Heart J. 2013;166(1):20-9.

51. Mullens W, Grimm RA, Verga T, et al. Insights from a cardiac resynchronization optimization clinic as part of a heart failure disease management program. J Am Coll Cardiol. 2009;53(9):765-73.

52. Sohaib SM, Whinnett ZI, Ellenbogen KA, et al. Cardiac resynchronisation therapy optimisation strategies: systematic classification, detailed analysis, minimum standards and a roadmap for development and testing. Int J Cardiol. 2013;170(2):118-31.

53. Pabari PA, Willson K, Stegemann B, et al. When is an optimization not an optimization? Evaluation of clinical implications of information content (signal-to-noise ratio) in optimization of cardiac resynchronization therapy, and how to measure and maximize it. Heart Fail Rev. 2011;16(3):277-90.
54. Sun JP, Lee AP, Grimm RA, et al. Optimisation of atrioventricular delay during exercise improves cardiac output in patients stabilised with cardiac resynchronisation therapy. Heart. 2012;98(1):54-9.

55. Stanton T, Haluska BA, Leano R, Marwick TH. Hemodynamic benefit of rest and exercise optimization of cardiac resynchronization therapy. Echocardiography. 2014;31(8):980-8.

56. Foley PW, Chalil S, Khadjooi K, Irwin N, Smith RE, Leyva F. Left ventricular reverse remodelling, long-term clinical outcome, and mode of death after cardiac resynchronization therapy. Eur J Heart Fail. 2011;13(1):43-51.

57. Yu CM, Bleeker GB, Fung JW, et al. Left ventricular reverse remodeling but not clinical improvement predicts long-term survival after cardiac resynchronization therapy. Circulation. 2005;112(11):1580-6.

58. Versteeg H, Sant J van 't, Cramer MJ, Doevendans PA, Pedersen SS, Meine M. Discrepancy between echocardiographic and patient-reported health status response to cardiac resynchronization therapy: results of the PSYHEART-CRT study. Eur J Heart Fail. 2014;16(2):227-34.

59. Ypenburg C, Bommel RJ van, Borleffs CJ, et al. Long-term prognosis after cardiac resynchronization therapy is related to the extent of left ventricular reverse remodeling at midterm follow-up. J Am Coll Cardiol. 2009;53(6):483-90.

60. Sant J van 't, Fiolet AT, Ter Horst IA, et al. Volumetric response beyond six months of cardiac resynchronization therapy and clinical outcome. PLoS One. 2015;10(5):e0124323. 